Article

\title{
A Novel Tb@Sr-MOF as Self-Calibrating Luminescent Sensor for Nutritional Antioxidant
}

\author{
Yi Wang ${ }^{1}$, Shaomin Lin ${ }^{2}$, Jun Luo ${ }^{1}$, Rui Huang ${ }^{2}$, Hong Cai ${ }^{2}$, Wei Yan ${ }^{1}$ and Huan Yang ${ }^{2, *}$ \\ 1 College of chemistry and Material Engineering, Gui Yang University, Guiyang 550005, China; \\ wangy49@mail2.sysu.edu.cn (Y.W.); 2243@hstc.edu.cn (J.L.); caolm3@mail2.sysu.edu.cn (W.Y.) \\ 2 School of Material science and Engineering Han Shan Normal University, Chaozhou 521041, China; \\ lsm678@hstc.edu.cn (S.L.); rhuang@hstc.edu.cn (R.H.); glcai@hstc.edu.cn (H.C.) \\ * Correspondence: yanghuan@hstc.edu.cn; Tel.: +86-076-8630-5234
}

Received: 10 September 2018; Accepted: 1 October 2018; Published: 7 October 2018

\begin{abstract}
Sesamol, is well-known antioxidant and can reduce the rate of oxidation and prolong expiration date. It is also potentially antimutagenic and antihepatotoxic, the detection of sesamol is important and remains a huge challenge. Herein, a new 3D alkaline earth $\mathrm{Sr}$ metal organic framework [Sr(BDC) $\left.\cdot \mathrm{DMAC} \cdot \mathrm{H}_{2} \mathrm{O}\right] \mathrm{n}$ (BDC = benzene-1,4-dicarboxylate; DMAC $=\mathrm{N}, \mathrm{N}$-dimethylacetamide) is synthesized and a probe based on $\mathrm{Tb}^{3+}$ functionalized Sr-MOF. The Tb(3+)@Sr-MOF showed good luminescence and thermal property. Due to the energy competition between sesamol and ligand, the luminescence intensity of sesamol increases meantime luminescence intensity of $\mathrm{Tb}^{3+}$ decreases, the ratio of the emission intensities $\left(\mathrm{I}_{344} / \mathrm{I}_{545}\right)$ linearly increases with sesamol in concentrations ranging from $1 \times 10^{-7}$ to $8 \times 10^{-4} \mathrm{M}$. Furthermore, the fluorescence-detected circular test shows that the composite $\mathrm{Tb}(3+) @ S r-\mathrm{MOF}$ can serve as ratiometric sensor for sensing of sesamol. This is the first example for self-calibrated detecting sesamol based on metal-organic framework (MOF).
\end{abstract}

Keywords: $\mathrm{Tb}$ (III) functionalized; metal organic framework; self-calibrating and reusable luminescent sensor; sesamol

\section{Introduction}

Sesame oil is a high-priced, high-quality health food that is popular in China and India because it contains a number of bioactive phytochemical; it is very high in natural antioxidants in the form of lignans. Antioxidant compounds in sesame seed oil that are beneficial impacts on health have attracted increasing attention. Sesamol (3,4-methylenedioxyphenol) is a natural phenolic lignan found in sesame seed or sesame oil as well as has shown promising antioxidant and neuroprotective effects $[1,2]$. Recently, tremendous research has shown that sesamol can weaken injury in endotoxemic rats, lower serum lipids and blood pressure; it also has potentially anti-hypertensive and anti-inflammatory activities in humans. Sesamol content plays an important role human health and the flavor of sesame oil, therefore there is a need for sesamol determination for evaluate lignan content in sesame oil or other food, meanwhile, determination of sesamol in different environment with high selectivity and sensitivity has also become a major research topic. Some detection methods for sesamol have been developed $[3,4]$ such as high-performance liquid chromatography (HPLC) or ultraviolet (UV) detection ultraviolet (UV) detection. However, many disadvantages have various limitations such as time-consuming, cost, complicated preparation process, and the need for professionals. Therefore, it is exigent to explore a kind of simple, rapid, highly selective, and sensitive access for detecting sesamol [5].

Metal-organic frameworks (MOFs), are crystalline porous architectures that are composed of metal ions or clusters and organic ligand, have been emerging as very promising materials which can 
be applied in various fields due to their unique properties, such as high surface areas, controllable pore size. MOFs have been proposed to be promising in many applications, such as gas storage and separation [6-11], catalysis [12-15], energy storage [16,17], and biomedical applications [18-23]. Among luminescent MOFs, Ln-MOFs have huge advantages in sensing due to their fascinating luminescence characteristics, such as high luminescence quantum yield, long luminescent life time, high color purity, and big stoke shifts. The prominent luminescent properties and various structures of Ln-MOFs provide a facile and easy method for detection [24-26] such as metal ions [27,28], anions [29-32], small molecule [33-36], and temperature [37,38]. Due to the high coordination number and multiple coordination modes of lanthanide ions, the design and preparation of the desired lanthanide MOF is also a huge challenge. Poststsynthetic modification method of MOFs provide an effective tool to perform the fluorescence sensing properties of lanthanide MOFs by introduction of $\mathrm{Ln}^{3+}$ into MOFs, which can exploit and expand their application [39-41]. In comparison to the reports on other metal organic framework, alkaline earth metals have been rarely reported, but alkaline earth metals have applied in many field of materials science because of some advantages (low-cost, avirulent). Based on aforementioned reasons, alkaline earth salts are usually used as commercial materials, which are extensively used in daily life and industry production, such as common medicament, dyes, and pigments. Some studies about alkaline earth metal complexes should be performed. $\mathrm{Mg}$ and Al based MOFs exhibit excellent hydrogen storage ability because of low density, high surface areas, and controlled structures [42,43].

In addition, MOF sensors depends on the fluorescent intensity of single emission which usually influenced by many uncontrollable factors such as drift of light source and sensor concentration. Therefore, dual-emissive luminescent probe should be one breakthrough because this type of signal by making a comparison of the emission intensities of two different luminescent center to form self-calibrating mechanism that can avoid external factor such as fluctuations of light source, voltage, show improved sensitivity, and to the intended analyte [44-47]. However, there is no report for self-calibrating MOF-based luminescent probe that can selectively detect antioxidant sesamol molecule.

Herein, according to the above considerations and our previous work on Ln-metal organic frameworks [48,49], a new 3D Sr metal-organic framework is designed and synthesized. $\mathrm{The} \mathrm{Tb}(3+) @ S r-M O F$ were successfully synthesized via encapsulating $\mathrm{Tb}^{3+}$ in $\mathrm{Sr}-\mathrm{MOF}$. When energy competition exists between sesamol and ligand, which blocks the energy transfer from ligand to $\mathrm{Tb}^{3+}$, hence the luminescent intensity of sesamol at $330 \mathrm{~nm}$ increases and $\mathrm{Tb}^{3+}$ ion at $545 \mathrm{~nm}$ decreases. A linear relationship between the ratio of luminescent intensities $\left(\mathrm{I}_{343} / \mathrm{I}_{545}\right)$ and the concentration of sesamol. Thus, this composite $\mathrm{Tb}(3+) @ S r-M O F$ can be served as a promising self-calibrating sensor for sesamol sensing.

\section{Experimental Section}

\subsection{Synthesis of $\left[\mathrm{Sr}(\mathrm{BDC}) \cdot \mathrm{DMAC} \cdot \mathrm{H}_{2} \mathrm{O}\right] n(\mathrm{Sr}-\mathrm{MOF})$}

A mixture of $\mathrm{SrCl}_{2}(0.1 \mathrm{mmol}, 15.7 \mathrm{mg})$ and $\mathrm{H}_{2} \mathrm{BDC}(0.1 \mathrm{mmol}, 16.6 \mathrm{mg})$ were stirred in $3 \mathrm{~mL}$ DMAC and added in a $15 \mathrm{~mL}$ Teflon cup and heated to $80^{\circ} \mathrm{C}$ for $72 \mathrm{~h}$ then cooled to room temperature. The colorless block single crystals were obtained, rinsed with DMAC and $\mathrm{H}_{2} \mathrm{O}$, and dried in air $(56 \%$ yield based on BDC).

\subsection{Synthesis of $T b(3+) @ S r-M O F$}

Powder of Sr-MOF $(100 \mathrm{mg})$ is soaked in $\mathrm{Tb}\left(\mathrm{NO}_{3}\right)_{3} \cdot 6 \mathrm{H}_{2} \mathrm{O}$ ethanol solution $(10 \mathrm{~mL}, 2 \mathrm{mmol})$ for 1 day. The powder is isolated by centrifugation and washed with ethanol three times, the obtained product dried in air for $24 \mathrm{~h}$. The metal amount of Tb:Sr is 1:22. 


\subsection{Detection of Sesamol}

The obtained Tb(3+)@Sr-MOF (2.00 mg) dispersed in $4 \mathrm{~mL}$ ethanol and ultrasonicated for $5 \mathrm{~min}$. Different concentrations of sesamol ethanol solutions were prepared and mixed with suspension of $\mathrm{Tb}(3+) @ S r-M O F$ for the detection of sesamol. For the selectivity of sesamol detection, $1 \times 10^{-3} \mathrm{M}$ for sesamol, 4-Methylcatechol, catechol, guaiacol, carvacrol, paeonol, thymol, vanillin, resorcinol, and 1,3-dichlorophenol were also prepared and added to each of the suspension of $\mathrm{Tb}(3+) @ S r-\mathrm{MOF}$, respectively. In order to examine the cycle performance of $\mathrm{Tb}(3+) @ S r-\mathrm{MOF}$, the suspension is formed by dispersing the sample $(1 \mathrm{mg} / \mathrm{mL})$ into ethanol. After detection of sesamol, the suspensions of $\mathrm{Tb}(3+) @ S r-M O F /$ sesamol are obtained by filtration and rinsed several times with ethanol, then the $\mathrm{Tb}(3+) @ S r-M O F$ was dried naturally and ready for the next cyclic test.

\subsection{Materials and Characterization}

Sesamol, 4-Methylcatechol, catechol, guaiacol, carvacrol, paeonol, thymol, vanillin, resorcinol, 1,3-dichlorophenol, terbium nitrate and Strontium chloride were purchased from Mackin (Macklin. Shanghai. China). The metal ion content in $\mathrm{Tb}(3+) @ S r-M O F(\mathrm{~Tb}: \mathrm{Sr})$ were examined using inductively coupled plasma mass spectrometry ICP-MS, Icap Qc (Thermo-Fisher, Massachusetts, MA, USA). X-ray diffraction (XRD) patterns were characterized using a Rigaku Miniflex 600 X-ray diffractometer (Rigadu, Tokyo, Japan) from $5^{\circ}$ to $50^{\circ}$. All the emission spectra for the $\mathrm{Tb}(3+) @ \mathrm{Sr}-\mathrm{MOF}$ were recorded by Horiba ihr320 fluorescence spectrophotometer(Horiba, Kyoto, Japan). An infrared spectrum was recorded and taken on a IR Affinity-1 FT-IR spectrometer (Shimadzu, Kyoto, Japan) in the range of 400-4000 $\mathrm{cm}^{-1}$. Thermogravimetric analysis (TGA) results were measured from $50{ }^{\circ} \mathrm{C}$ to $700{ }^{\circ} \mathrm{C}$ under nitrogen atmosphere on a Netzsch sta $449 \mathrm{f} 3$ (Netzsch, Bararia, Germany).

\subsection{X-ray Crystallography}

Crystal of Sr-MOF was collected from the mother liquor. Single-crystal data of Sr-MOF were collected on a Rigaku Oxford CCD diffractometer equipped with graphite-monochromatic Mo-K $\alpha$ radiation $(\lambda=0.71073 \AA)$ at $293 \mathrm{~K}$. The structure was solved by direct methods, and refined by full-matrix least-square method with the SHELX-2016 program package. The crystallographic data and refinements and the selected bond lengths and angles for Sr-MOF are listed in Tables 1 and 2.

Table 1. Crystal data and structure refinement for Sr-MOF.

\begin{tabular}{cc}
\hline Compound & Sr-MOF \\
\hline Chemical Formula & $\mathrm{C}_{12} \mathrm{H}_{15} \mathrm{NO}_{6} \mathrm{Sr}$ \\
Formula weight & 356.87 \\
Crystal system & Orthorhombic \\
Space group & Pnma \\
$a(\AA)$ & $10.9304(3)$ \\
$b(\AA)$ & $6.96110(10)$ \\
$c(\AA)$ & $19.0421(4)$ \\
$\alpha\left(^{\circ}\right)$ & 90 \\
$\beta\left(^{\circ}\right)$ & 90 \\
$\gamma\left(\left(^{\circ}\right)\right.$ & 90 \\
$V\left(\AA^{3}\right)$ & 1488.87 \\
$Z$ & 4 \\
$D_{c}\left(\mathrm{~g} / \mathrm{cm}^{3}\right)$ & 1.636 \\
$\mu\left(\mathrm{mm}^{-1}\right)$ & 1.347 \\
$T(\mathrm{~K})$ & $293(2)$ \\
Mo Kalpha & 1.54178 \\
$F(000)$ & 720 \\
Crystal size $(\mathrm{mm})$ & $0.23 \times 0.19 \times 0.15$ \\
$\theta$ range $\left(^{\circ}\right)$ & 4.64 to 67.08 \\
\hline
\end{tabular}


Table 1. Cont

\begin{tabular}{cc}
\hline Compound & Sr-MOF \\
\hline Index ranges & $-11 \leq \mathrm{h} \leq 12$ \\
& $-6 \leq \mathrm{k} \leq 8$ \\
& $-22 \leq 1 \leq 22$ \\
Reflections collected & 6263 \\
Independent reflections & $1398\left[\mathrm{R}_{\text {int }}=0.0326\right]$ \\
Parameters & 109 \\
Goodness-of-fit on $F^{2}$ & 1.112 \\
$R_{1}$ indices $[I>2 \sigma(I)]$ & 0.0340 \\
$w R_{2}$ indices $[I>2 \sigma(I)]$ & 0.0878 \\
$R_{1}$ indices [all data] & 0.0369 \\
$w R_{2}$ indices [all data] & 0.0902 \\
\hline
\end{tabular}

Table 2. Bond lengths [A] and angles [deg] for Sr-MOF.

\begin{tabular}{c}
\hline Main Coordination Modes Bond Length \\
\hline $\operatorname{Sr}(1)-\mathrm{O}(2) \# 12.490(2)$ \\
$\operatorname{Sr}(1)-\mathrm{O}(2) \# 22.490(2)$ \\
$\mathrm{Sr}(1)-\mathrm{O}(3) 2.496(4)$ \\
$\mathrm{Sr}(1)-\mathrm{O}(4) 2.570(3)$ \\
$\mathrm{Sr}(1)-\mathrm{O}(1) 2.642(2)$ \\
$\mathrm{Sr}(1)-\mathrm{O}(1) \# 32.642(2)$ \\
$\mathrm{Sr}(1)-\mathrm{O}(2) \# 42.689(2)$ \\
$\mathrm{Sr}(1)-\mathrm{O}(2) \# 52.689(2)$ \\
$\mathrm{Sr}(1)-\mathrm{C}(6) \# 42.971(5)$ \\
$\mathrm{O}(2)-\operatorname{Sr}(1) \# 82.490(2)$ \\
$\mathrm{O}(2)-\mathrm{Sr}(1) \# 92.689(2)$ \\
\hline Symmetry transformations used to generate equivalent atoms: \\
$\# 1-\mathrm{x}+1 / 2,-\mathrm{y}+1, \mathrm{z}-1 / 2 \# 2-\mathrm{x}+1 / 2, \mathrm{y}+1 / 2, \mathrm{z}-1 / 2$ \\
$\# 3 \mathrm{x},-\mathrm{y}+3 / 2, \mathrm{z} \# 4 \mathrm{x}-1 / 2, \mathrm{y},-\mathrm{z}+1 / 2 \# 5 \mathrm{x}-1 / 2,-\mathrm{y}+3 / 2,-\mathrm{z}+1 / 2$ \\
$\# 6-\mathrm{x},-\mathrm{y}+1,-\mathrm{z} \# 7-\mathrm{x},-\mathrm{y}+2,-\mathrm{z} \# 8-\mathrm{x}+1 / 2,-\mathrm{y}+1, \mathrm{z}+1 / 2$ \\
$\# 9 \mathrm{x}+1 / 2, \mathrm{y},-\mathrm{z}+1 / 2$ \\
\\
\end{tabular}

\section{Results and Discussion}

The crystals of Sr-BDC belong to the orthorhombic space group Pnma, the asymmetric unit is made up of half a $\mathrm{Sr}^{2+}$ ion, half a $\mathrm{BDC}^{2-}$ ligand, half a DMA, and half a water molecules (Figure 1a). The $\mathrm{Sr}^{2+}$ ion is bound to eight $\mathrm{O}$ atoms from one $\mathrm{H}_{2} \mathrm{O}$, one DMAC and four $\mathrm{BDC}^{2-}$ ligands, which form an octahedron which adopted distorted bicapped coordination. The DMAC and $\mathrm{H}_{2} \mathrm{O}$ are monodentate, and the $\mathrm{COO}^{-}$of a $\mathrm{BDC}^{2-}$ adopted two coordination modes with $\mathrm{Sr}^{2+}$ ions: $\eta 1: \eta 1$ and $\eta 2: \eta 2-$ bridging mode, which link one and three $\mathrm{Sr}^{2+}$ ion. In Figure 1b, in the bicapped octahedron, the $\mathrm{Sr}-\mathrm{O}$ bond distance vary from $2.490(6)$ to $2.687(5) \AA$. A zigzag chain is formed by adjacent octahedra along the $\mathrm{b}$ axis, and the chains are connected by the $\mathrm{BDC}^{2-}(\mu 4, \eta 1: \eta 1: \eta 2: \eta 2$-bridging mode) forming $\mathrm{a}$ three-dimensional framework, (Figure 1), which form quadrangular channel (two kinds of triangular channels), DMAC molecules are filled and connected directly to the $\mathrm{Sr}^{2+}$ ions in the channels.

The XRD patterns of simulated and as-synthesized Sr-MOF, Tb(3+)@Sr-MOF are shown in Figure 2. All the diffraction peaks (the Sr-MOF and $\mathrm{Tb}(3+) @ S r-\mathrm{MOF}$ ) were well corresponded to those in the simulated PXRD pattern of Sr-MOF(CCDC:1551141). The introduction of $\mathrm{Tb}^{3+}$ will not influence the crystal form of Sr-MOF. 


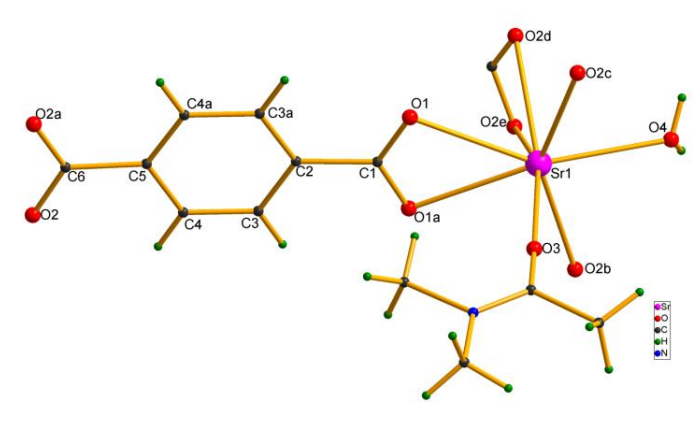

(a)

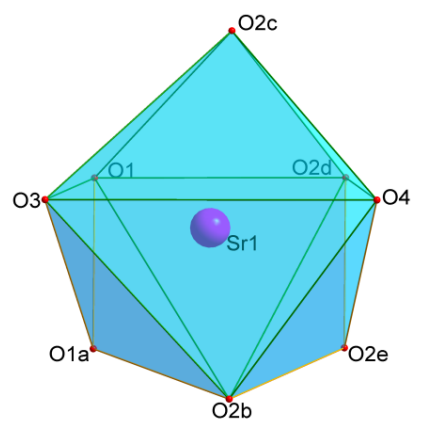

(b)
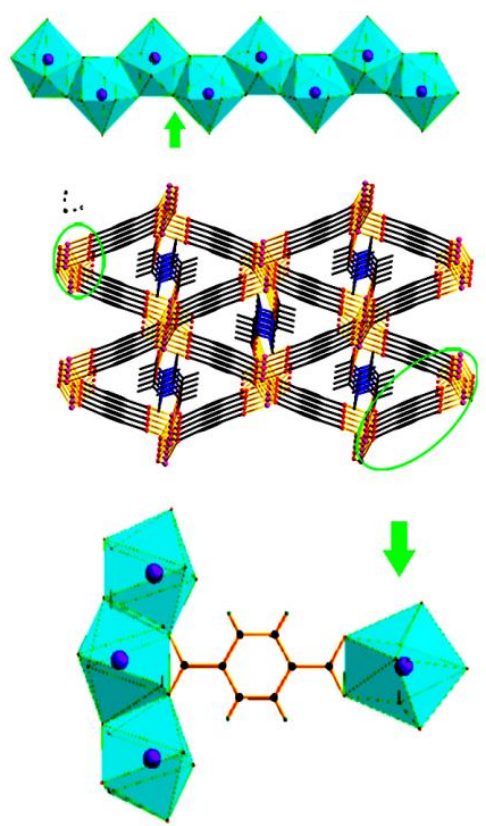

(c)

Figure 1. (a) Asymmetric unit of Sr-MOF. (b) Coordination mode of the $\mathrm{Sr}^{2+}$ ion. Atoms marked with are at the following symmetry positions: $a=x, 1.5-y, z ; b=0.5-x, 1-y,-0.5+z ; c=0.5-x, 0.5+y$, $-0.5+\mathrm{z} ; \mathrm{d}=-0.5+\mathrm{x}, 1.5-\mathrm{y}, 0.5-\mathrm{z} ; \mathrm{e}=-0.5+\mathrm{x}, \mathrm{y}, 0.5-\mathrm{z}$. (c) Packing diagram of 1 projected along the $c$ axis, showing the chains of bicapped octahedra and the connectivity between them.

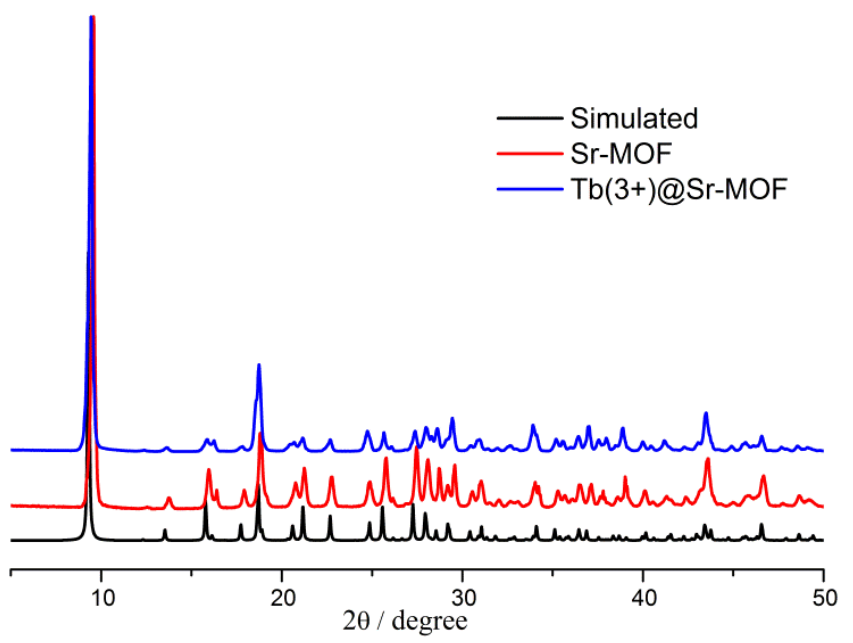

Figure 2. PXRD patterns of the simulated Sr-MOF, Tb(3+)@Sr-MOF. 
As shown in Figure 3, the TG measurement show that Tb@Sr-MOF and Sr-MOF similar thermal stability and exhibit three events of mass (Tb@Sr-MOF and Sr-MOF) reduction. The TG curve shows that Tb@Sr-MOF and Sr-MOF starts to reduce mass at $\sim 130{ }^{\circ} \mathrm{C}$ due to the removal of water molecules and complete dehydration is at about $200{ }^{\circ} \mathrm{C}$. The second plateau of reducing mass start from $200{ }^{\circ} \mathrm{C}$ to $310{ }^{\circ} \mathrm{C}$ corresponds to the loss of DMAC. The decomposition of the organic ligand begins at $580^{\circ} \mathrm{C}$ and ends at $630^{\circ} \mathrm{C}$. The final stage of reducing mass start from $630{ }^{\circ} \mathrm{C}$ corresponds to oxide.

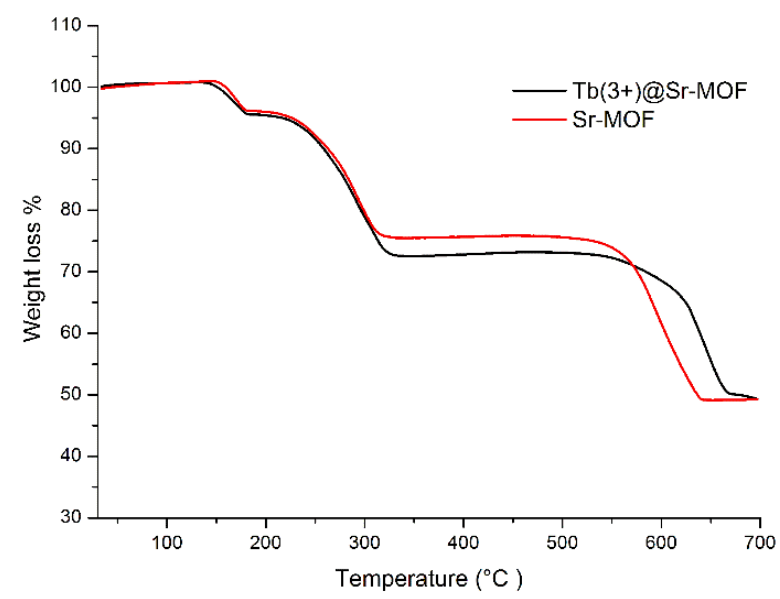

Figure 3. TGA of $\mathrm{Sr}-\mathrm{MOF}$ and $\mathrm{Tb}(3+) @ S r-\mathrm{MOF}$.

As shown in Figure 4, the broad band at $3300-3500 \mathrm{~cm}^{-1}$ is assigned to the characteristic stretching vibrations of $\mathrm{O}-\mathrm{H}$ in $\mathrm{H}_{2} \mathrm{O}$. The peak at $1560 \mathrm{~cm}^{-1}$ belongs to $v_{\mathrm{C}-\mathrm{O}}$. After incorporating $\mathrm{Tb}^{3+}$ into the Sr-MOF, the absorption band of $\mathrm{Tb}(3+) @ S r-M O F$ agrees with those of Sr-MOF. The result shows that the introduction of $\mathrm{Tb}^{3+}$ does not affect the crystalline integrity, as shown in Figure 2.

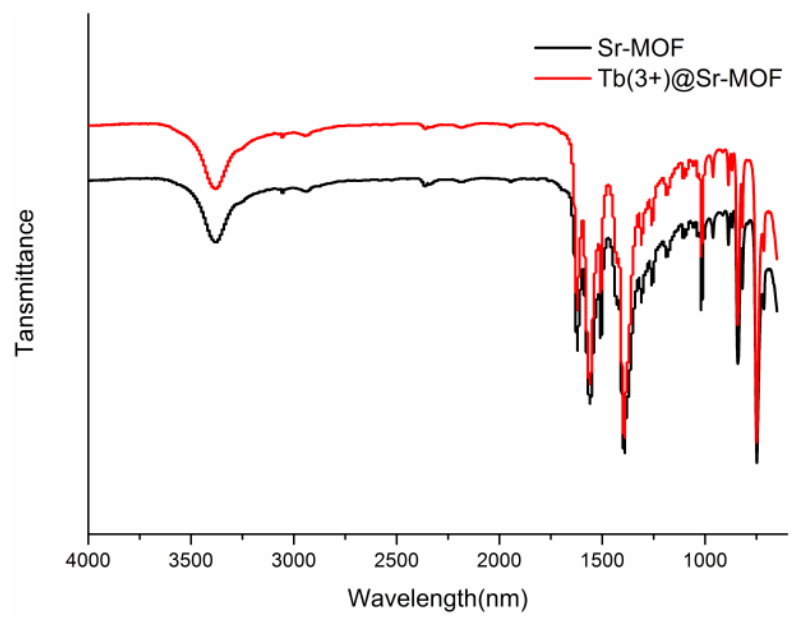

Figure 4. IR spectra of Sr-MOF and $\mathrm{Tb}(3+) @ S r-M O F$.

As seen in Figure 5, $\mathrm{Tb}(3+) @ S r-M O F$ exhibits characteristic emission of the $\mathrm{Tb}^{3+}$ ion when excited $294 \mathrm{~nm}$. Tb(3+)@Sr-MOF exhibits three peaks at 489, 545, and $592 \mathrm{~nm}$ originated from ${ }^{5} \mathrm{D}_{4} \rightarrow{ }^{7} \mathrm{~F}_{\mathrm{J}}$ $(\mathrm{J}=6,5,4)$ transitions, respectively. The emission bands of the $\mathrm{Tb}(3+) @ S r-\mathrm{MOF}$ at $545 \mathrm{~nm}$ show a bright green light. The results suggested $\mathrm{Tb}(3+) @ S r-M O F$ can act as a luminescence sensor.

The sensing ability of the $\mathrm{Tb}(3+) @ S r-M O F$ was investigated in the presence of different molecules. As shown in Figure 6, on the addition of $1 \times 10^{-3} \mathrm{M}$ of biomolecules (sesamol, 4-Methylcatechol, catechol, guaiacol, carvacrol, paeonol, thymol, vanillin, resorcinol, and 1,3-dichlorophenol), however, the luminescence intensity of $\mathrm{Tb}(3+) @ S r-M O F$ at $545 \mathrm{~nm}$ exhibit the strongest luminescence quenching in the presence of sesamol, meantime, and luminescent intensity (the emission at $330 \mathrm{~nm}$ ) increases 
significantly with the increasing the concentration of sesamol, We speculate that the emission spectrum at $330 \mathrm{~nm}$ is ascribed to sesamol.

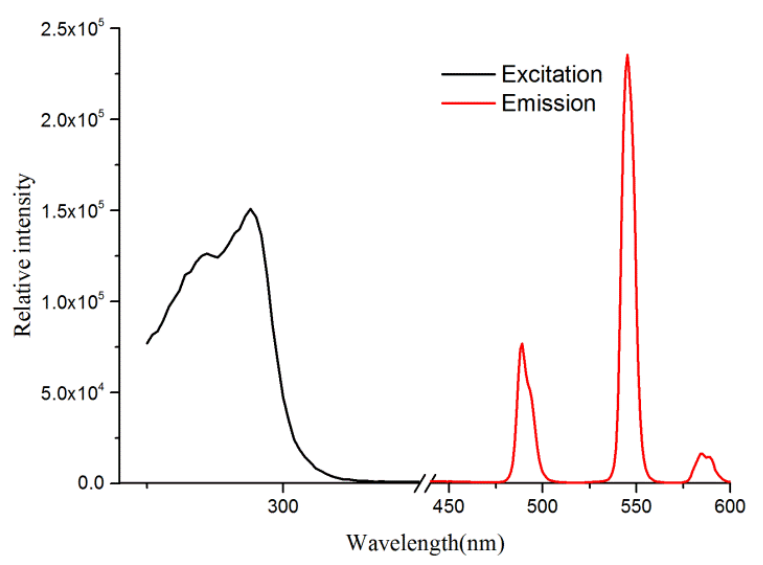

Figure 5. The excitation (dashed) and emission (solid) spectra of the Tb(3+)@Sr-MOF.

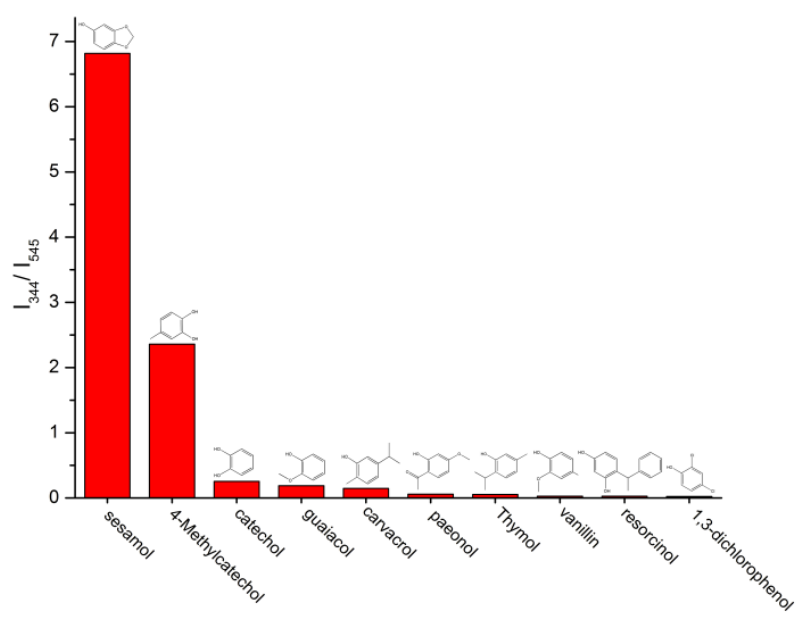

Figure 6. Diagrams of the transition intensities $\left(\mathrm{I}_{344} / \mathrm{I}_{545}\right)$ of the Tb@Sr-MOF in various small biomolecules $(\lambda e x=294 \mathrm{~nm})$.

In order to overcome such disadvantages of the traditional single emission sensing, $\mathrm{Tb}(3+) @ S r-M O F$ were synthesized and could be served as ratiometric luminescent sensor for sesamol. In Figure 7, the change of luminescent intensity $(\mathrm{Tb}(3+) @ S r-M O F)$ displayed with a concentration of sesamol increases. The luminescent intensity at $330 \mathrm{~nm}$ increased meantime the fluorescence intensity of $\mathrm{Tb}^{3+}$ at $545 \mathrm{~nm}$ decreased. The plot of the luminescent intensity ratio $\mathrm{I}_{330} / \mathrm{I}_{545}$ against the concentration of added sesamol was shown in Figure $7 \mathrm{a}, \mathrm{b}$, the luminescent intensity ratio $\mathrm{I}_{330} / \mathrm{I}_{545}$ has a good linear relationship to the concentration of sesamol varying from $1 \times 10^{-7}$ to $2 \times 10^{-4}$ $\mathrm{M}$ and $3 \times 10^{-4}$ to $8 \times 10^{-4} \mathrm{M}$, which was described by calibrating function of $\mathrm{I}_{330} / \mathrm{I}_{545}=0.00538+$ $0.0184 \times \mathrm{C}$ and $\mathrm{I}_{330} / \mathrm{I}_{545}=0.005 \times$ Csesamol-0.18 with a correlation coefficient of 0.99966 and 0.9887 . Interestingly, when the concentration of sesamol reaches $3 \times 10^{-4} \mathrm{M}$, luminescent intensities of $\mathrm{I}_{330}$ and $\mathrm{I}_{545}$ decreases, respectively. The luminescent intensity ratio $\mathrm{I}_{330} / \mathrm{I}_{545}$ also has a good linear correlation to the concentration of sesamol in the range from $1 \times 10^{-7}$ to $8 \times 10^{-4} \mathrm{M}$ calibrating function of $\mathrm{I}_{330} / \mathrm{I}_{545}=0.02+0.005 \times \mathrm{C}$ sesamol with a correlation coefficient of 0.9977 . The limit of detection $(\mathrm{LOD}=3 \delta / \mathrm{S}, \delta$ represents the blank solution was measured ten times, and $\mathrm{S}$ stands for the slope of the calibration curve was about $4.2 \mu \mathrm{M}$ [50]. The above results illustrated that $\mathrm{Tb}(3+) @ \mathrm{Sr}-\mathrm{MOF}$ is an excellent candidate for self-calibrating luminescent sensor (sesamol) and is not influenced by environmental factors. 


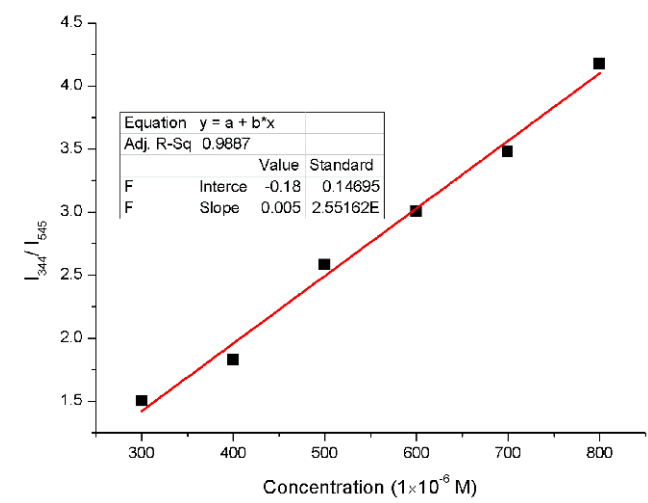

(a)

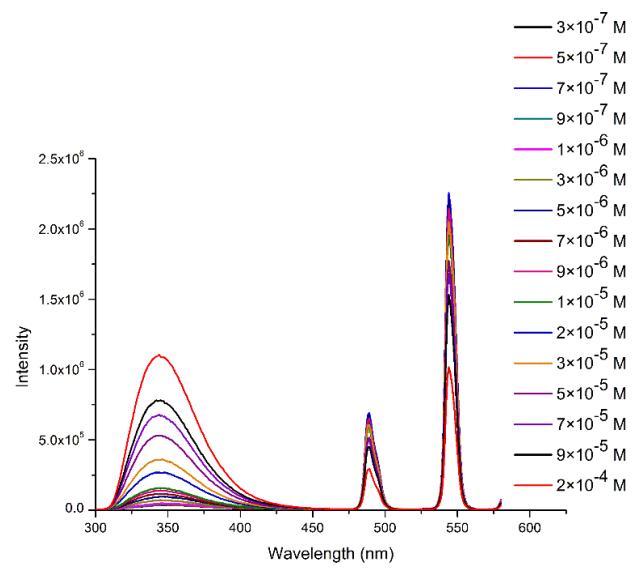

(c)

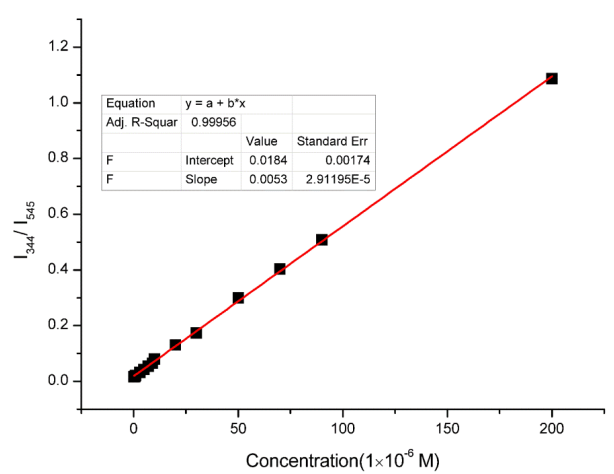

(b)

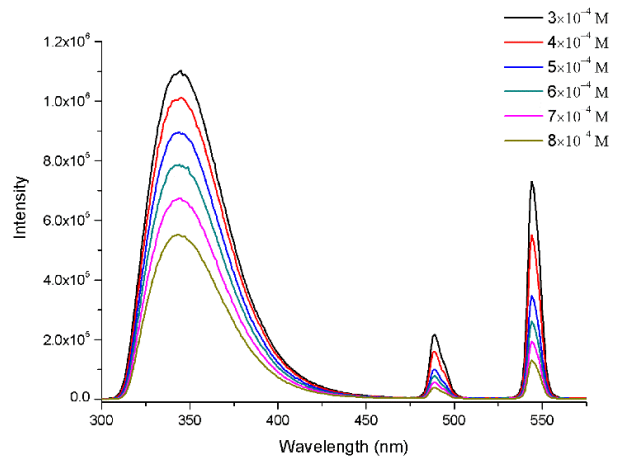

(d)

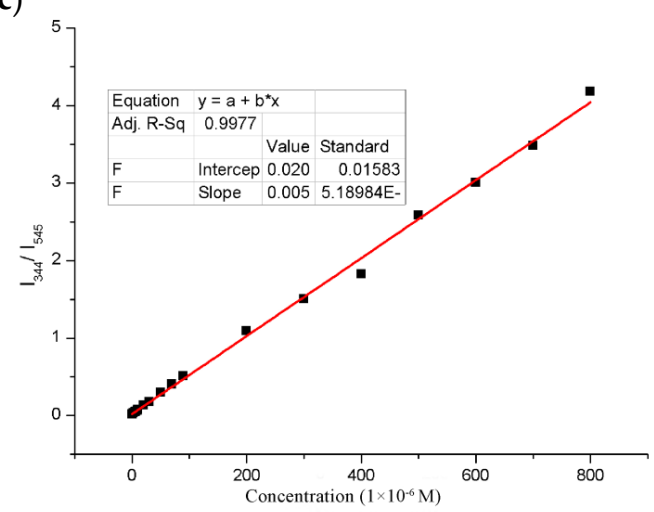

(e)

Figure 7. (a) Plot of $\mathrm{I}_{344} / \mathrm{I}_{545}$ versus the sesamol content $\left(1 \times 10^{-7}\right.$ to $\left.2 \times 10^{-4} \mathrm{M}\right)$ in ethanol solution $\left(\lambda_{\mathrm{ex}}=294 \mathrm{~nm}\right)$; (b) Plot of $\mathrm{I}_{344} / \mathrm{I}_{545}$ versus the sesamol content $\left(3 \times 10^{-4}\right.$ to $\left.8 \times 10^{-4} \mathrm{M}\right)$ in ethanol solution; (c) Emission spectra of $\mathrm{Tb}(3+) @ S r-M O F$ as a function of the sesamol concentration (from top: $1 \times 10^{-7}$ to $2 \times 10^{-4} \mathrm{M}$ ) in ethanol solution; (d) Emission spectra of Tb(3+)@Sr-MOF as a function of the sesamol concentration $\left(3 \times 10^{-4}\right.$ to $\left.8 \times 10^{-4} \mathrm{M}\right)$ in ethanol solution; (e) Plot of $\mathrm{I}_{344} / \mathrm{I}_{545}$ versus the sesamol content $\left(1 \times 10^{-7}\right.$ to $\left.8 \times 10^{-4} \mathrm{M}\right)$ in ethanol solution $\left(\lambda_{\mathrm{ex}}=294 \mathrm{~nm}\right)$.

The CIE (Commission International deLEclairage) diagram of the $\mathrm{Tb}(3+) @ \mathrm{Sr}-\mathrm{MOF}$ treated with different concentrations of sesamol was performed. As shown in Figure 8, luminescent color of $\mathrm{Tb}(3+) @ S r-M O F$ tuned from blue to green when excited at $294 \mathrm{~nm}$. The results show that the luminescent ratio $\left(\mathrm{I}_{344} / \mathrm{I}_{545}\right)$ is highly sensitive to the concentration of sesamol. The feature could be used served for sensing of different concentrations of sesamol with high selectivity and sensitivity and without any addition. 


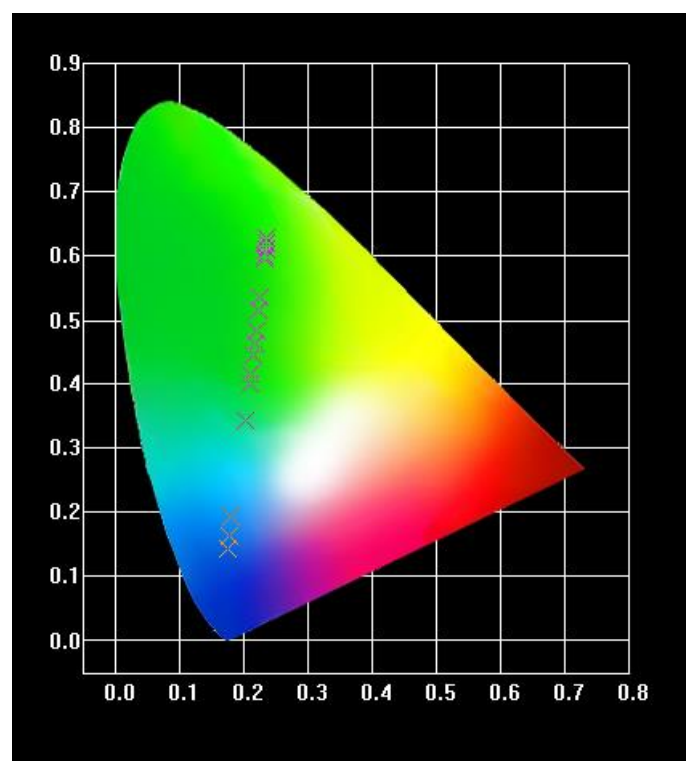

Figure 8. CIE chromaticity coordinates.

From a practical standpoint, the probe should have good response and high selectivity to the detecting. As seen in Figure 9, to access the selectivity of $\mathrm{Tb}(3+) @ S r-M O F$, the competitive experiment was performed by adding $1 \times 10^{-3} \mathrm{M}$ sesamol to the $\mathrm{Tb}(3+) @ S r-M O F$ in the presence of $1 \times 10^{-3}$ $\mathrm{M}$ other biomolecules (including 4-Methylcatechol, catechol, guaiacol, thymol, carvacrol, resorcinol, vanillin, and paeonol). The addition of biomolecules will not influence the changed trend of the ratio of $\mathrm{I}_{330} / \mathrm{I}_{545}$. (colorful columns in Figure 4), However, when added $1 \times 10^{-3} \mathrm{M}$ sesamol to the $\mathrm{Tb}(3+) @ S r-M O F$ containing other biomolecules, the luminescent intensity ratio $\mathrm{I}_{330} / \mathrm{I}_{545}$ increased remarkably (blue columns in Figure 4). Therefore, the results show that the Tb(3+)@Sr-MOF is a reliable and high-efficient self-calibrating sensor for sesamol.

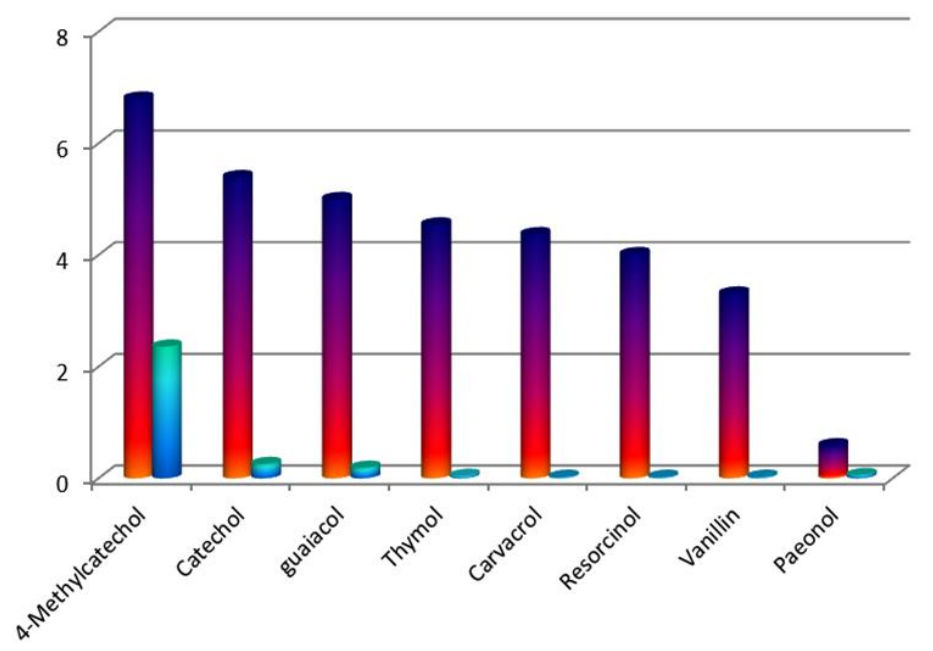

Figure 9. Luminescence responses of $\mathrm{Tb}(3+) @ S r-\mathrm{MOF}$ to various biomolecules. The color bars suggest the relative ratio of luminescent intensities $\left(\mathrm{I}_{344} / \mathrm{I}_{545}\right)$ treated with biomolecules. The blue bars suggest the relative ratio of $\mathrm{I}_{344} / \mathrm{I}_{545}$ treated with other biomolecules and sesamol) $\left(\lambda_{\mathrm{ex}}=294 \mathrm{~nm}\right)$.

Furthermore, the cycling ability is an important indicator to access the sensor's practicability. $\mathrm{The} \mathrm{Tb}(3+) @ S r-M O F$ can be reused five times (Figure 10). After five cycles, the results show that the luminescence intensity of the recycled $\mathrm{Tb}(3+) @ S r-M O F$ almost agrees with those of the initial $\mathrm{Tb}(3+) @ S r-M O F$, Meanwhile, These results reveal that $\mathrm{Tb}(3+) @ S r-M O F$ displays well reusability of sensing sesamol, suggesting its practical use in sesamol detection. 


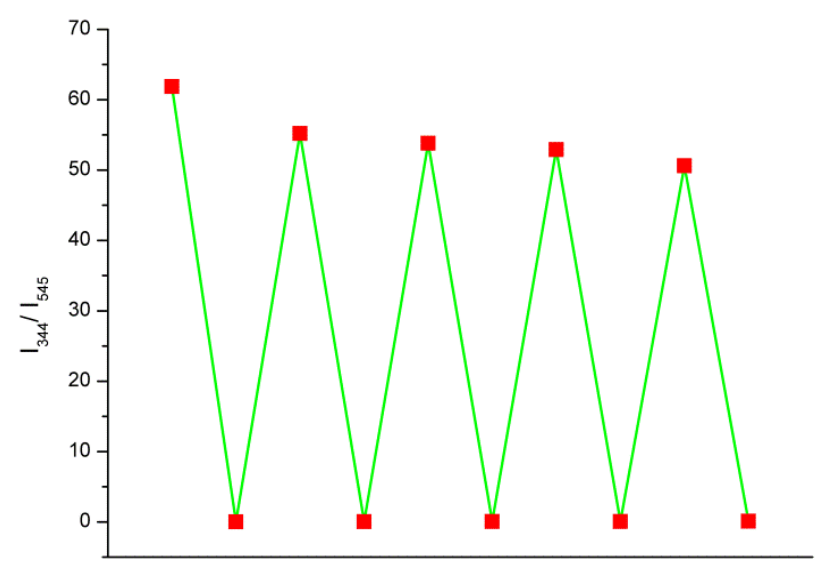

Figure 10. Cyclic response of luminescence intensities $\left(\mathrm{I}_{344} / \mathrm{I}_{545}\right)$ of the $\mathrm{Tb}(3+) @ S r-\mathrm{MOF}$ for detecting sesamol.

While the quenching mechanism for biomolecules is still not very clear, it is necessary to study the possible quenching mechanism. (1) The emission spectra of sesamol was monitored when excited $294 \mathrm{~nm}$, as shown in Figure 11, the $\mathrm{I}_{344}$ is consistent with $\mathrm{I}_{344}$ in Figure 7c,d. The result shows that luminescent signal $\left(\mathrm{I}_{344}\right)$ in Figure $7 \mathrm{c}, \mathrm{d}$ is assigned to sesamol. (2) As shown in Figure S1, the excitation spectra of the ligand within $\mathrm{Tb}(3+) @ S r-M O F$ is overlapped by the excitation spectra of sesamol, which suggests an excitation energy competition between the ligand and sesamol exists. Sesamol absorbs most of the energy and only a small fraction of energy will be transferred from the linker to the $\mathrm{Tb}^{3+}$ ions. The PXRD patterns of the $\mathrm{Tb}(3+) @ S r-M O F$ treated with sesamol reveal that its crystal structure is not changed and is consistent with the original Tb(3+)@Sr-MOF (as shown in Figure S2). (3) To better understand why luminescent intensities of $\mathrm{I}_{344}$ and $\mathrm{I}_{545}$ decreases when concentration of sesamol reached $3 \times 10^{-4} \mathrm{M}$, we monitored the excitation spectra of $\mathrm{Tb}(3+) @ \mathrm{Sr}-\mathrm{MOF}$ treated with various concentrations of sesamol under the monitoring wavelength $(545 \mathrm{~nm})$. As shown in Figure 12, with the increased concentration of sesamol, the intensities of excitation spectra of $\mathrm{Tb}(3+) @ S r-M O F$ decreases and a blue shift in the excitation maxima(294 to280 nm) could be observed for $\mathrm{Tb}(3+) @ S r-M O F$ treated with different concentrations of sesamol, leading to decline in luminescent intensity $\left(\mathrm{I}_{344}\right.$ and $\left.\mathrm{I}_{545}\right)$, respectively, the fluorescence intensity ratio $\mathrm{I}_{330} / \mathrm{I}_{545}$ has also a good linear relationship to the concentration of sesamol vary from $1 \times 10^{-7}$ to $8 \times 10^{-4} \mathrm{M}$, The results suggested that $\mathrm{Tb}(3+) @ S r-M O F$ can serve as a self-calibrating luminescent sensor for sesamol and is not influenced by environmental factors.

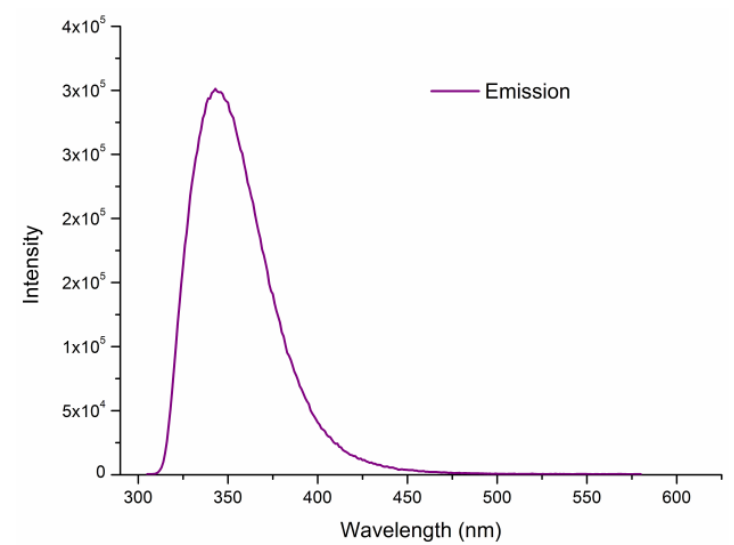

Figure 11. The emission (solid) spectra of the sesamol $\left(\lambda_{\mathrm{ex}}=294 \mathrm{~nm}\right)$. 


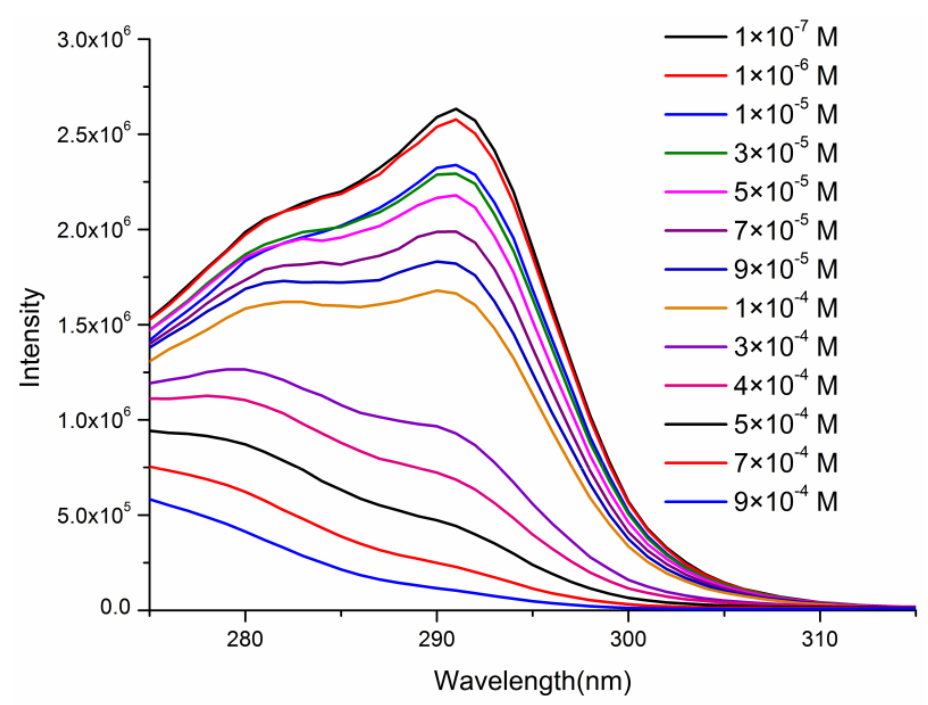

Figure 12. The excitation spectra of the $\mathrm{Tb}(3+) @ S r-M O F$ treated with sesamol.

\section{Conclusions}

In summary, a new 3D alkaline earth Sr metal organic framework is synthesized and chosen as a host to sensitize via encapsulating $\mathrm{Tb}^{3+}$ in Sr-MOF. $\mathrm{Tb}(3+) @ S r-M O F$ display excellent luminescent property and thermal stability. Due to energy competition between sesamol and ligand, the luminescent intensity of sesamol $\left(\mathrm{I}_{344}\right)$ increases meantime luminescence intensity of $\mathrm{Tb}^{3+}\left(\mathrm{I}_{545}\right)$ decreases. $\mathrm{The} \mathrm{Tb}(3+) @ S r-M O F$ can be used as ratiometric sensor for sesamol. It is the first time reported that the rational design and preparation of luminescent $\mathrm{MOFs}$ for ratiometric sensing of sesamol relying on the ratio of emission-peak-height of analyte (sesamol) to lanthanide ions $\left(\mathrm{Tb}^{3+}\right)$ as the detectable signals. In addition, this strategy may promote the development of lanthanide functionalized MOF for self-calibrating sensing and broaden the application of alkaline earth metal organic framework.

Supplementary Materials: Materials and Methods are available online at http:/ / www.mdpi.com/2079-4991/8/ 10/796/s1, Figure S1: The excitation spectra of sesamol(monitored wavelength 330nm), Figure S2: PXRD patterns of the Tb(3+)@Sr-MOF treated with sesamol $\left(1 \times 10^{-2} \mathrm{M}\right)$.

Author Contributions: Data curation, Y.W. and W.Y.; Formal analysis, J.L.; Investigation, S.L. and H.C.; Methodology, R.H.; Writing-original draft, Y.W.; Writing-review \& editing, H.Y.

Acknowledgments: The project was supported by Guizhou youth science and technology talents project(2017243), the special funding of Guiyang science and technology bureau and Guiyang University GYU-KYZ(2018)03-07, Major construction project of first-rate university in Guizhou provice (2017158134) and National Natural Science Foundation of China(21701038).

Conflicts of Interest: The authors declare no conflict of interest.

\section{References}

1. Yashaswini, P.S.; Kurrey, N.K.; Singh, S.A. Encapsulation of sesamol in phosphatidyl choline micelles: Enhanced bioavailability and anti-inflammatory activity. Food Chem. 2017, 228, 330-337. [CrossRef] [PubMed]

2. Liu, Z.G.; Sun, Y.L.; Qiao, Q.L.; Zhao, T.; Zhang, W.T.; Ren, B.; Liu, X.B. Sesamol ameliorates high-fat and high-fructose induced cognitive defects via improving insulin signaling disruption in the central nervous system. Food Funct. 2017, 8, 710-719. [CrossRef] [PubMed]

3. Liu, Z.G.; Ren, B.; Wang, Y.H.; Zou, C.; Qiao, Q.L.; Diao, Z.J.; Mi, Y.S.; Zhu, D.; Liu, X.B. Sesamol induces human hepatocellular carcinoma cells apoptosis by impairing mitochondrial function and suppressing autophagy. Sci. Rep. 2017, 7, 47528. [CrossRef] [PubMed]

4. Liu, B.; Liu, J.; Sun, P.P.; Ma, X.N.; Jiang, Y.; Chen, F. Sesamol enhances cell growth and the biosynthesis and accumulation of docosahexaenoic acid in the microalga crypthecodinium cohnii. J. Agric. Food Chem. 2015, 63, 5640-5645. [CrossRef] [PubMed] 
5. Liu, H.; Wu, D.; Liu, Y.; Zhang, H.; Ma, T.; Aidaerhan, A.; Wang, J.; Sun, B. Application of an optosensing chip based on molecularly imprinted polymer coated quantum dots for the highly selective and sensitive determination of sesamol in sesame oils. J. Agric. Food Chem. 2015, 11, 2545-2549. [CrossRef] [PubMed]

6. Chen, F.L.; Wang, Y.; Bai, D.J.; He, M.H.; Gao, X.X.; He, Y.B. Selective adsorption of $\mathrm{C}_{2} \mathrm{H}_{2}$ and $\mathrm{CO}_{2} \mathrm{from}_{\mathrm{CH}_{4}}$ in an isoreticular series of MOFs constructed from unsymmetrical diisophthalate linkers and the effect of alkoxy group functionalization on gas adsorption. J. Mater. Chem. A 2018, 6, 3471-3478. [CrossRef]

7. Silva, P.; Vilela, S.M.F.; Tomé, J.P.C.; Almeida Paz, F.A. Multifunctional metal-organic frameworks: From academia to industrial applications. Chem. Soc. Rev. 2015, 44, 6774-6803. [CrossRef] [PubMed]

8. Bao, Z.B.; Chang, G.G.; Xing, H.B.; Krishna, R.; Ren, Q.L.; Chen, B.L. Potential of microporous metal-organic frameworks for separation of hydrocarbon mixtures. Energy Environ. Sci. 2016, 9, 3612-3641. [CrossRef]

9. Li, B.; Wen, H.M.; Cui, Y.J.; Zhou, W.; Qian, G.D.; Chen, B.L. Emerging multifunctional metal-organic framework materials. Adv. Mater. 2016, 28, 8819-8860. [CrossRef] [PubMed]

10. Voorde, B.V.; Bueken, B.; Denayer, J.; Vos, D.D. Adsorptive separation on metal-organic frameworks in the liquid phase. Chem. Soc. Rev. 2014, 43, 5766-5788. [CrossRef] [PubMed]

11. Modena, M.M.; Hirschle, P.; Wuttke, S.; Burg, T.P. Mass measurements reveal preferential sorption of mixed solvent components in porous nanoparticles. Small 2018, 14, 1800826. [CrossRef] [PubMed]

12. Liu, J.W.; Chen, L.F.; Cui, H.; Zhang, J.Y.; Su, C.Y. Applications of metal-organic frameworks in heterogeneous supramolecular catalysis. Chem. Soc. Rev. 2014, 43, 6011-6061. [CrossRef] [PubMed]

13. Rogge, S.M.J.; Bavykina, A.; Hajek, J.; Garcia, H.; Olivos-Suarez, A.I.; Sepúlveda-Escribano, A.; Vimont, A.; Clet, G.; Bazin., P.; Kapteijn, F.; et al. Metal-organic and covalent organic frameworks as single-site catalysts. Chem. Soc. Rev. 2017, 46, 3134-3184. [CrossRef] [PubMed]

14. Wang, T.; Jin, R.M.; Wu, Y.; Zheng, J.; Li, X.G. Chemical induced fragmentation of MOFs for highly efficient Ni-based hydrogen evolution catalysts. Nanoscale Horiz. 2018, 3, 218-225. [CrossRef]

15. Chughtai, A.H.; Ahmad, N.; Younus, H.A.; Laypkov, A.; Verpoort, F. Metal-organic frameworks: Versatile heterogeneous catalysts for efficient catalytic organic transformations. Chem. Soc. Rev. 2015, 44, 6804-6849. [CrossRef] [PubMed]

16. Liu, J.X.; Wöll, C. Surface-supported metal-organic framework thin films: Fabrication methods, applications, and challenges. Chem. Soc. Rev. 2017, 46, 5730-5770. [CrossRef] [PubMed]

17. Zhu, Q.L.; Xu, Q. Metal-organic framework composites. Chem. Soc. Rev. 2014, 43, 5468-5512. [CrossRef] [PubMed]

18. Freund, R.; Lächelt, U.; Gruber, T.; Rühle, B.; Wuttke, S. Multifunctional efficiency: Extending the concept of atom economy to functional nanomaterials. ACS Nano 2018, 12, 2094-2105. [CrossRef] [PubMed]

19. Chen, W.; Wu, C.S. Synthesis, functionalization, and applications of metal-organic frameworks in biomedicine. Dalton Trans. 2018, 47, 2114-2133. [CrossRef] [PubMed]

20. Wuttke, S.; Lismont, M.; Escudero, A.; Rungtaweevoranit, B.; Parak, W.J. Positioning metal-organic framework nanoparticles within the context of drug delivery-A comparison with mesoporous silica nanoparticles and dendrimers. Biomaterials 2017, 123, 172-183. [CrossRef] [PubMed]

21. Simon-Yarza, T.; Mielcarek, A.; Couvreur, P.; Serre, C. Nanoparticles of metal-organic frameworks: On the road to in vivo efficacy in biomedicine. Adv. Mater. 2018, 111, 1707365. [CrossRef] [PubMed]

22. Wang, S.Z.; McGuirk, C.M.; d'Aquino, A.; Mason, J.A.; Mirkin, C.A. Metal-organic framework nanoparticles. Adv. Mater. 2018, 423, 1800202. [CrossRef] [PubMed]

23. Lismont, M.; Dreesen, L.; Wuttke, S. Metal-Organic Framework Nanoparticles in Photodynamic Therapy: Current Status and Perspectives. Adv. Funct. Mater. 2017, 27, 1606314. [CrossRef]

24. Meyer, L.V.; Schönfeld, F.; Müller-Buschbaum, K. Lanthanide based tuning of luminescence in MOFs and dense frameworks-from mono- and multimetal systems to sensors and films. Chem. Commun. 2014, 50, 8093-8108. [CrossRef] [PubMed]

25. Heffern, M.C.; Matosziuk, L.M.; Meade, T.J. Lanthanide probes for bioresponsive imaging. Chem. Rev. 2014, 114, 4496-4539. [CrossRef] [PubMed]

26. Qin, X.; Liu, X.W.; Huang, W.; Bettinelli, M.; Liu, X.G. Lanthanide-activated phosphors based on 4f-5d optical transitions: Theoretical and experimental aspects. Chem. Rev. 2017, 117, 4488-4527. [CrossRef] [PubMed]

27. Cao, L.H.; Shi, F.; Zhang, W.M.; Zang, S.Q.; Mak, T.C.W. Selective sensing of $\mathrm{Fe}^{3+}$ and $\mathrm{Al}^{3+}$ ions and detection of 2,4,6-trinitrophenol by a water-stable terbium-based metal-organic framework. Chem. A Eur. J. 2015, 21, 15705-15712. [CrossRef] [PubMed] 
28. Yan, W.; Zhang, C.L.; Chen, S.G.; Han, L.J.; Zheng, H.G. Two lanthanide metal-organic frameworks as remarkably selective and sensitive bifunctional luminescence sensor for metal ions and small organic molecules. ACS Appl. Mater. Interfaces 2017, 9, 1629-1634. [CrossRef] [PubMed]

29. Hinterholzinger, F.M.; Rühle, B.; Wuttke, S.; Karaghiosoff, K.; Bein, T. Highly sensitive and selective fluoride detection in water through fluorophore release from a metal-organic framework. Sci. Rep. 2013, 3, 2562. [CrossRef] [PubMed]

30. Ding, B.; Liu, S.X.; Cheng, Y.; Guo, C.; Wu, X.X.; Guo, J.H.; Liu, Y.Y.; Li, Y. Heterometallic alkaline earth-lanthanide BaII-LaIII microporous metal-organic framework as bifunctional luminescent probes of $\mathrm{Al}^{3+}$ and $\mathrm{MnO}^{4-}$. Inorg. Chem. 2016, 55, 4391-4402. [CrossRef] [PubMed]

31. Chen, B.L.; Wang, L.B.; Zapata, F.; Qian, G.D.; Lobkovsky, E.B. A luminescent microporous metal-organic framework for the recognition and sensing of anions. J. Am. Chem. Soc. 2008, 130, 6718-6719. [CrossRef] [PubMed]

32. Chu, T.S.; Zhang, F.; Wang, Y.; Yang, Y.Y.; Ng, S.W. A novel electrophoretic deposited coordination supramolecular network film for detecting phosphate and biophosphate. Chem. A Eur. J. 2017, 32, 7748-7754. [CrossRef] [PubMed]

33. Qin, Z.S.; Dong, W.W.; Zhao, J.; Wu, Y.P.; Zhang, Q.C.; Li, D.S. A water-stable Tb(III)-based metal-organic gel(MOG) for detection of antibiotics and explosives. Inorg. Chem. Front. 2017, 5, 120-126. [CrossRef]

34. Zhang, S.Y.; Shi, W.; Cheng, P.; Zaworotko, M.J. A mixed-crystal lanthanide Zeolite-like metal-organic framework as a fluorescent indicator for Lysophosphatidic Acid, a cancer biomarker. J. Am. Chem. Soc. 2015, 137, 12203-12206. [CrossRef] [PubMed]

35. Zhang, F.; Yao, H.; Chu, T.S.; Zhang, G.W.; Wang, Y.; Yang, Y.Y. The $\mathrm{Co}_{3} \mathrm{O}_{4}$ nano-anchors fixed Ln-MOF thin film as a highly efficient luminescent sensor for nitrofuran antibiotics. Chem. Eur. J. 2017, 23, 10293-10300. [CrossRef] [PubMed]

36. Wuttke, S.; Dietl, C.; Hinterholzinger, F.M.; Hintz, H.; Langhalsa, H.; Bein, T. Turn-on fluorescence triggered by selective internal dye replacement in MOFs. Chem. Commun. 2014, 50, 3599-3601. [CrossRef] [PubMed]

37. Feng, J.F.; Gao, S.Y.; Liu, T.F.; Shi, J.L.; Cao, R. Preparation of dual-emitting Ln@UiO-66-Hybrid films via electrophoretic deposition for ratiometric temperature sensing. ACS Appl. Mater. Interfaces 2018, 10, 6014-6023. [CrossRef] [PubMed]

38. Rao, X.T.; Song, T.; Gao, J.K.; Cui, Y.J.; Yang, Y.; Wu, C.D.; Chen, B.L.; Qian, G.D. A highly sensitive mixed lanthanide metal organic framework self-calibrated luminescent thermometer. J. Am. Chem. Soc. 2013, 135, 15559-15564. [CrossRef] [PubMed]

39. Xu, X.Y.; Yan, B. Intelligent molecular searcher from logic computing network based on Eu(III) functionalized UMOFs for environmental monitoring. Adv. Funct. Mater. 2017, 27, 1700247. [CrossRef]

40. Yan, B. Lanthanide-functionalized metal-organic framework hybrid systems to create multiple luminescent centers for chemical sensing. Acc. Chem. Res. 2017, 50, 2789-2798. [CrossRef] [PubMed]

41. Dou, Z.S.; Yu, J.C.; Cui, Y.J.; Yang, Y.; Wang, Z.Y.; Yang, D.R.; Qian, G.D. Luminescent metal-organic framework films as highly sensitive and fast-response oxygen sensors. J. Am. Chem. Soc. 2014, 136, 5527-5530. [CrossRef] [PubMed]

42. Douvali, A.; Tsipis, A.C.; Eliseeva, S.V.; Petoud, S.; Papaefstathiou, G.S.; Malliakas, C.D.; Papadas, I.; Armatas, G.S.; Margiolaki, I.; Kanatzidis, M.G.; et al. Turn-on luminescence sensing and real-time detection of traces of water in organic solvents by a flexible metal-organic framework. Angew. Chem. Int. Ed. Engl. 2015, 54, 1651-1656. [CrossRef] [PubMed]

43. Cooper, L.; Hidalgo, T.; Gorman, M.; Lozano-Fernández, T.; Simón-Vázquez, R.; Olivier, C.; Guillou, N.; Serre, C.; Martineau, C.; Taulelle, F.; et al. A biocompatible porous Mg-gallate metal-organic framework as an antioxidant carrier. Chem. Commun. 2015, 51, 5848-5851. [CrossRef] [PubMed]

44. Zhou, J.M.; Li, H.H.; Zhang, H.; Li, H.M.; Shi, W.; Cheng, P.A. Bimetallic lanthanide metal-organic material as a self-calibrating color-gradient luminescent sensor. Adv. Mater. 2015, 27, 7072-7077. [CrossRef] [PubMed]

45. Zhao, H.; Ni, J.; Zhang, J.J.; Liu, S.Q.; Sun, Y.J.; Zhou, H.J.; Li, Y.Q.; Duan, C.Y. A trichromatic MOF composite for multidimensional ratiometric luminescent sensing. Chem. Sci. 2018, 9, 2918-2926. [CrossRef] [PubMed]

46. Gao, J.; Wang, C.H.; Tan, H.L. Dual-emissive polystyrene@zeolitic imidazolate framework-8 composite for ratiometric detection of singlet oxygen. J. Mater. Chem. B 2017, 5, 9175-9182. [CrossRef] 
47. Schrimpf, W.; Jiang, J.; Ji, Z.; Hirschle, P.; Lamb, D.C.; Yaghi, O.M.; Wuttke, S. Chemical diversity in a metal-organic framework revealed by fluorescence lifetime imaging. Nat. Commun. 2018, 9, 1647. [CrossRef] [PubMed]

48. Wang, Y.; Huang, R.; Zhang, J.J.; Cheng, G.; Yang, H. Lanthanide( $\mathrm{Tb}^{3+}$, $\left.\mathrm{Eu}^{3+}\right)$-functionalized a new one dimensional Zn-MOF composite as luminescent probe for highly selectively sensing $\mathrm{Fe}^{3+}$. Polyhedron 2018, 148, 178-183. [CrossRef]

49. Wang, Y.; Yang, H.; Cheng, G.; Wu, Y.Y.; Lin, S.M. A new Tb(III )-functionalized layer-like Cd MOF as luminescent probe for high-selectively sensing of $\mathrm{Cr}^{3+}$. CrystEngComm 2017, 19, 7270-7276. [CrossRef]

50. Yue, D.; Huang, Y.K.; Zhang, L.; Jiang, K.; Zhang, X.; Cui, Y.J.; Yu, Y.; Qian, G.D. Ratiometric luminescence sensing based on a mixed Ce/Eu metal-organic framework. J. Mater. Chem. C 2018, 6, 2054-2059. [CrossRef]

2018 by the authors. Licensee MDPI, Basel, Switzerland. This article is an open access article distributed under the terms and conditions of the Creative Commons Attribution (CC BY) license (http:/ / creativecommons.org/licenses/by/4.0/). 